\title{
Efeito imunossupressor da ciclosporina intra-muscular administrada em diferentes períodos pós-operatórios em um modelo de transplante penetrante de córnea em ratos
}

\author{
Immunosuppressive effect of intramuscular cyclosporine used at different post- \\ operative period on a penetrating keratoplasty model in the rat
}

Roberto von Hertwig (1)

Moacyr Pezati Rigueiro ${ }^{(2)}$

Paulo Dantas Rodrigues ${ }^{(3)}$

Franco Amboni Nunes Tôrres ${ }^{(4)}$

Mauro Nishi ${ }^{(5)}$
Trabalho desenvolvido nos Departamentos de Oftalmologia e Anatomia Patológica da Universidade Federal de São Paulo - Escola Paulista de Medicina e no Curso de Medicina da Universidade Regional de Blumenau - FURB.

Os autores afirmam não haver qualquer interesse comercial no assunto e nos materiais utilizados.

Professor da Área de Oftalmologia do Curso de Medicina da FURB - Universidade Regional de Blumenau.

Professor Adjunto do Departamento de Patologia da UNIFESP.

Mestre em Oftalmologia pela UNIFESP.

(4) Acadêmico do $6^{\circ}$ ano do Curso de Medicina da FURB

- Universidade Regional de Blumenau.

Professor Orientador de Pós-Graduação da UNIFESP

Endereço para correspondência: Roberto von Hertwig. Rua Itajaí, 417. Blumenau (SC). CEP $89015-$ 200. e-mail: rhertwig@zaz.com.br

RESUMO
Objetivo: Avaliar o efeito imunossupressor da ciclosporina
intramuscular (I.M.), administrada por tempo limitado em diferen-
tes períodos do pós-operatório, no transplante penetrante de córnea
em um modelo experimental em rato, por meio de avaliação clínica e
anátomo-patológica do enxerto corneano.
Método: Foram utilizados ratos isogênicos Fischer como doadores
e Lewis como receptores, em um modelo ortotópico de transplante de
córnea. A administração de ciclosporina I.M. 10 mg/kg/dia foi inicia-
da em diferentes períodos nos grupos estudados: no pós-operatório
imediato, no $7^{\circ}$ dia pós-operatório e no $9^{\circ}$ dia pós-operatório. A
ciclosporina quando iniciada foi administrada até o $30^{\circ}$ dia pós-
operatório. Um grupo controle não recebeu a ciclosporina I.M. Os
enxertos corneanos foram avaliadas clínica e histologicamente.
Resultados: Rejeição foi observada nas primeiras três semanas do
pós-operatório em $100 \%$ dos casos no grupo controle (n=5) que não
recebeu a ciclosporina. Os ratos tratados com ciclosporina (n = 15)
apresentaram rejeição em apenas um caso, que teve curta evolução e
poucos sinais clínicos. Os estudos histológicos confirmaram as avalia-
ções clínicas. O grupo controle apresentou infiltrado no enxerto
corneal com predomínio de linfócitos sobre neutrófilos com mais
neovasos, com mais fibrose e com infiltrado inflamatório mais intenso
do que os grupos tratados com ciclosporina.
Conclusão: Os dados obtidos indicam que a ciclosporina I.M.,
pode ter efeito benéfico sobre o controle da rejeição do transplante de
córnea, mesmo na sua fase ativa.

Palavras-chave: Ciclosporina A; Transplante de córnea experimental; Rejeição do enxerto.

\section{INTRODUCÃO}

A despeito dos avanços no campo da microcirurgia, do conhecimento da importância da manutenção da integridade do endotélio e da progressiva melhora na preservação corneal entre outros fatores, a rejeição ainda é a causa da falência do enxerto ${ }^{1}$. A córnea transplantada pode desencadear uma resposta imune, que resulta em sua destruição e compromete sua capacidade funcional ${ }^{2}$. As estatísticas variam entre 5 a $10 \%$ de casos que evoluem para falência quando o leito receptor da córnea é avascular ${ }^{3}$. 
Entretanto, quando o leito receptor da córnea é vascularizado ou após rejeições corneais prévias, este índice passa a ser maior que $50 \%$ de falência corneal devido a rejeição imunológica ${ }^{1}$.

$\mathrm{O}$ uso de corticosteróides controla apenas aproximadamente $50 \%$ dos casos de córneas rejeitadas ${ }^{4}$ e se justifica portanto o interesse sobre novas formas de prevenção e tratamento para o grupo de transplantes de córnea com alto risco de rejeição. Vários autores demonstraram aumento no tempo de sobrevida dos enxertos de córnea, utilizando a ciclosporina (CSA) em diferentes animais, por períodos limitados ${ }^{2,5}$. Aumento da sobrevivência de enxertos corneanos com o uso de ciclosporina oral em combinação com corticóides sistêmicos foi demonstrado em humanos ${ }^{6}$. Apesar da comprovada eficácia imunossupressora da ciclosporina no controle da rejeição do transplante penetrante de córnea, alguns pontos não estão totalmente esclarecidos. Pela sua ação inibidora na maturação dos linfócitos $\mathrm{T}$, a ciclosporina tem sido utilizada nas fases iniciais do transplante, ou seja, antes de se realizar a cirurgia ou no pós-operatório imediato. Alguns autores obtiveram êxito em atenuar e até mesmo reverter episódios iniciais da rejeição com o uso da ciclosporina ${ }^{7}$, o que torna discutível qual o melhor momento para iniciar o tratamento com a droga a fim de se obter controle na rejeição do transplante de córnea ${ }^{8}$. Ainda é controverso se a ciclosporina é eficaz no controle de reações imunes em andamento o que significaria atuar durante a crise de rejeição ${ }^{9}$.

O objetivo deste estudo foi avaliar o efeito imunossupressor da ciclosporina intramuscular, administrada por tempo limitado em diferentes períodos do pós-operatório, no transplante penetrante de córnea em um modelo experimental em rato, através de avaliação clínica e anátomo-patológica do enxerto corneano.

\section{MATERIAL E MÉTODO}

\section{Animais utilizados}

Foram utilizados 10 ratos isogênicos Fischer 344 (F344/ NHsd) como doadores e 20 ratos isogênicos Lewis (LEW/ $\mathrm{SsNHsd)} \mathrm{como} \mathrm{receptores} \mathrm{de} \mathrm{córneas.} \mathrm{Os} \mathrm{animais} \mathrm{foram} \mathrm{obti-}$ dos do Instituto Harlan Sprague Dawley, INC, (Indianapolis, IN, EEUU) e compreendiam adultos jovens, tanto machos como fêmeas e pesavam entre 200 e 250 gramas no momento da cirurgia.

Os ratos isogênicos Lewis e Fisher diferem quanto aos antígenos de histocompatibilidade média e menor (medial, minor histocompatibily antigens) ${ }^{10}$.

Os animais foram mantidos em biotério à temperatura de $22^{\circ} \mathrm{C} \pm 2$, com água acidificada e comida (ração Nuvital CR1 para ratos) "ad libidum", intercalando 12 horas de luz e escuridão, limpeza e troca da serragem de pinus branca diária das gaiolas. As experiências com os animais de laboratório seguiram protocolo aprovado pela comissão de ética do Hospital São Paulo da Universidade Federal de São Paulo, Escola Paulista de Medicina.

\section{Delineamento experimental}

Ratos isogênicos Lewis como receptores e ratos isogênicos Fisher como doadores foram submetidos a transplante alogênico de córnea e divididos em 4 grupos de acordo com a administração I.M. de ciclosporina.

Grupo Controle: sem administração de ciclosporina.

Grupo T 0: início da administração diária da ciclosporina no pós-operatório imediato.

Grupo T 7: início da administração diária de ciclosporina no $7^{\circ}$ dia pós-operatório.

Grupo T 9: início da administração diária de ciclosporina no $9^{\circ}$ dia pós-operatório.

A dose diária de ciclosporina I.M. utilizada foi de $10 \mathrm{mg} / \mathrm{kg}$ de peso, até 30 dias de pós-operatório. Cada grupo foi composto por 5 ratos.

\section{Procedimento cirúrgico}

Os ratos foram anestesiados com injeção I.M. de hidrocloridrato de quetamina $250 \mathrm{mg} / \mathrm{kg}$ de peso e xilazina $80 \mathrm{mg} / \mathrm{kg}$ de peso. Midríase foi obtida instilando-se gotas de colírio de tropicamida 1\% (Mydriacyl 1\% - Alcon, São Paulo), sulfato de fenilefrina 10\% (Fenilefrina 10\% - Frumtost, São Paulo), e sulfato de atropina 1\% (Atropina 1\% - Frumtost, São Paulo). Cada colírio foi instilado 3 vezes, com intervalos de 10 minutos, meia hora antes da cirurgia. Os ratos foram fixados em decúbito lateral com fitas adesivas e a assepsia do campo operatório foi realizada utilizando-se iodo ativo a 1,0\% (iodo povidona- Glicolabor- Ribeirão Preto, SP). Os animais foram cobertos com campos operatórios fenestrados expondo-se a área a ser operada. A técnica cirúrgica utilizada neste estudo foi originalmente descrita por Herbort et $a^{11}$. Após a fixação do globo ocular, trepanação corneal excêntrica com trépano de $3 \mathrm{~mm}$ de diâmetro foi realizado nos ratos doadores (ratos isogênicos Fischer). Dois enxertos foram obtidos de cada rato doador. Estes foram sacrificados imediatamente após o procedimento através de superdosagem anestésica. As córneas doadoras foram mantidas em solução de preservação para córnea (Likorol - Opsia-Pharma, França) com 1 ponto de sutura de mononylon 10-0 (Ethicon 9000G - Johnson \& Johnson, São Paulo) transfixando a periferia corneal. Para a preparação do leito receptor, ratos isogênicos Lewis foram submetidos a trepanação central com trépano de $2,5 \mathrm{~mm}$ de diâmetro. A córnea doadora foi suturada ao leito receptor com 8 pontos separados, com fios de sutura mononylon 10-0 (Ethicon Johnson \& Johnson, São Paulo). Após a conclusão das suturas, a câmara anterior foi preenchida com ar. Utilizou-se pomada oftálmica de tobramicina (Tobrex - Alcon, São Paulo) na ferida operatória, realizando-se em seguida, tarsorrafia com fio de sutura seda preta 6.0 (Ethicon - Johnson \& Johnson, São Paulo) que foi removido após 3 dias. Todo procedimento cirúrgico foi realizado sob assepsia cirúrgica e com auxílio de microscópio cirúrgico (DF Vasconcelos, modelo MCM 5, São Paulo). 


\section{Avaliação clínica pós-operatória}

As córneas transplantadas foram examinadas diariamente através de microscópio cirúrgico pelo mesmo examinador de forma mascarada. Estas córneas foram avaliadas clinicamente e classificadas utilizando-se os critérios que se seguem. Opacificação da córnea doadora: avaliação com classificação "0" se não houvesse nenhuma opacificação; "1" se discreta opacificação estivesse presente mas que ainda permitia clara visualização de detalhes da íris; "2" se os detalhes da íris eram vistos com dificuldade devido a opacidade corneana; " 3 " se houvesse opacidade extrema mas com a pupila ainda visível; "4" se a opacidade da córnea fosse total. Edema da córnea doadora: " 0 " se houvesse ausência de edema; "1" se discreto edema de córnea estivesse presente; " 2 " se houvesse edema significativo com elevação do botão, facilmente observável em sua borda. Neovasos na córnea doadora: "0" se não houvessem neovasos no botão doador; "1" se os neovasos atingissem o terço periférico do botão doador; "2" se os neovasos atingissem o terço médio do botão doador; " 3 " se os neovasos atingissem o terço central do botão doador.

$\mathrm{O}$ enxerto corneano foi considerado rejeitado após a primeira semana, se a soma dos critérios de avaliação fosse superior a 8. Os animais foram sacrificados com superdosagem anestésica, no $30^{\circ}$ dia pós-operatório (P.O.) e o enxerto encaminhado para o estudo histológico.

\section{Estudo histológico}

Os olhos enucleados foram fixados em formol a $10 \%$ por um mínimo de 24 horas e a seguir desidratados em álcool $70^{\circ}$ por mais 24 horas. Estes globos foram então seccionados ao meio, de maneira a representar o nervo e a córnea nos dois pólos do corte (plano mediano ântero-posterior) e então processados rotineiramente pelas técnicas usuais para inclusão em parafina.

Cortes histológicos da região para-central da córnea, de 5 micrômetros de espessura, foram preparados e corados pela técnica da hematoxilina-eosina ${ }^{12}$. Os cortes histológicos foram examinados em microscópio óptico para avaliação do grau de infiltrado inflamatório, do tipo celular predominante, da presença de vascularização e de fibrose. Esta avaliação foi realizada de maneira semi-quantitativa, atribuindo-se os seguintes valores para marcação dos achados: classificação "0" se os achados fossem ausentes; "+" se fossem leves; "++" se moderados; "+++" se fossem acentuados. O predomínio de linfócitos ou neutrófilos, também foi avaliado de maneira semi-quantitativa considerando-se as seguintes situações: "=" para quantidades semelhantes; ">” se houvesse leve predomínio de um tipo; ">>” se houvesse acentuado predomínio de um tipo. As córneas foram avaliadas de forma mascarada por patologista do Departamento de Patologia da Universidade Federal de São Paulo - Escola Paulista de Medicina.

\section{Análise estatística}

Os resultados clínicos observados foram avaliados estatis- ticamente entre o $7^{\circ}$ e $30^{\circ}$ dia pós-operatório. Para isto utilizou-se o teste de Wilcoxon-Rank Sum ${ }^{13}$ e nível de significância $\mathrm{P}<0,01$.

\section{RESULTADOS}

\section{Avaliação clínica}

Observou-se que a média dos parâmetros clínicos dos enxertos de todos os grupos foram elevados e tiveram evolução semelhante até aproximadamente o $8^{\circ}$ e $9^{\circ}$ dia pósoperatório. A partir daí, a média da avaliação clínica do grupo controle aumentou enquanto a dos demais grupos regrediram progressivamente até o final do período de estudo, como mostram a figura e a tabela 1 . Observa-se que a média das somas dos critérios de avaliação clínica dos enxertos do grupo controle é a única que se encontra acima de 8 (considerada rejeitada) a partir do $13^{\circ}$ e $14^{\circ}$ dia pós-operatório assim permanecendo até o $30^{\circ}$ dia, ao contrário dos grupos tratados com ciclosporina onde as médias tendem a diminuir neste mesmo período. A análise estatística comparando as médias das avaliações clínicas mostra que existe diferença significante entre o grupo controle se comparado com os demais grupos que receberam ciclosporina, ou seja, $\mathrm{T} 0, \mathrm{~T} 7 \mathrm{e} \mathrm{T} 9(\mathrm{P}=$ 0,0001 para todas as comparações). Não existe diferença significante entre os grupos T0 e T7 $(\mathrm{P}=0,2115)$ e existe diferença significante entre os grupos T0 e T9 $(\mathrm{P}=0,0001)$.

A maioria dos animais do grupo controle tiveram seus enxertos rejeitados em torno do $14^{\circ}$ dia pós-operatório e no restante do grupo a rejeição ocorreu até o $19^{\circ}$ dia pós-operató-

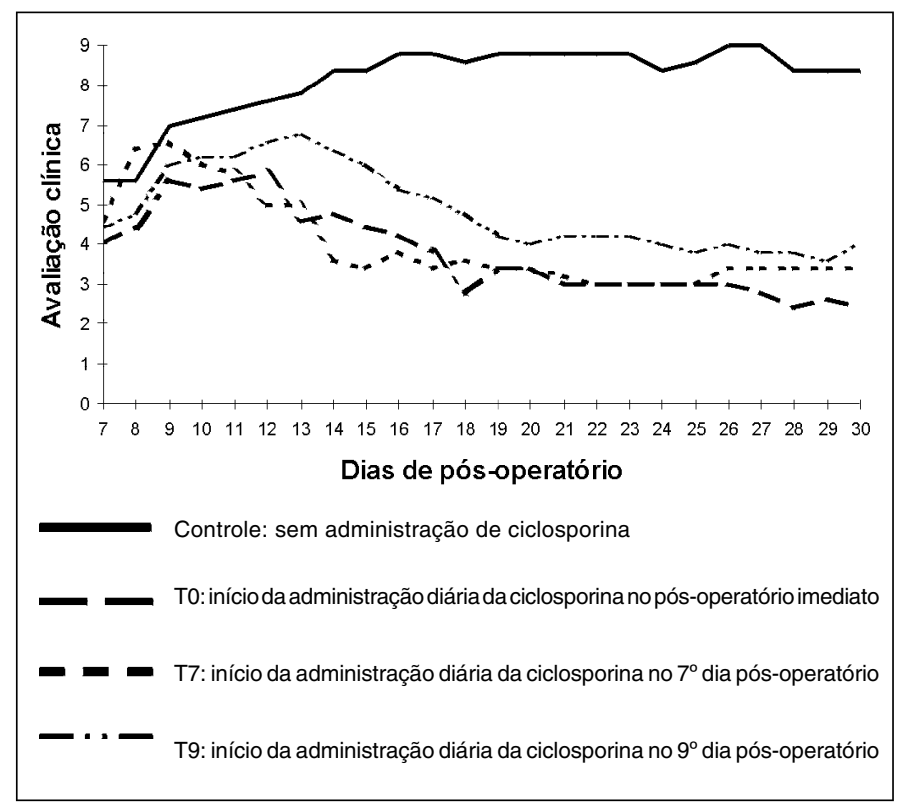

Fig. 1 - Média das somas dos critérios de avaliação clínica dos enxertos corneanos nos diferentes grupos. Todos os grupos tratados com ciclosporina tiveram evolução significantemente diferente do grupo controle $(p<0,0001)$ 


\begin{tabular}{|c|c|c|c|c|}
\hline \multicolumn{5}{|c|}{$\begin{array}{l}\text { Tabela 1. Média e desvios-padrão das somas dos critérios de } \\
\text { avaliação clínica dos enxertos corneanos nos diferentes grupos }\end{array}$} \\
\hline \multirow{2}{*}{$\begin{array}{l}\text { Dias de Pós- } \\
\text { Operatório }\end{array}$} & \multicolumn{4}{|c|}{ Grupos } \\
\hline & Controle & T0 & T7 & T9 \\
\hline 7 & $5,6 \pm 1,14$ & $4,0 \pm 1,87$ & $4,6 \pm 0,89$ & $4,6 \pm 0,89$ \\
\hline 8 & $5,6 \pm 1,14$ & $4,4 \pm 1,14$ & $6,4 \pm 0,54$ & $4,8 \pm 1,09$ \\
\hline 9 & $7,0 \pm 1,22$ & $5,6 \pm 1,81$ & $6,6 \pm 0,54$ & $5,8 \pm 1,48$ \\
\hline 10 & $7,2 \pm 0,83$ & $5,4 \pm 1,67$ & $6,0 \pm 1,58$ & $6,2 \pm 1,09$ \\
\hline 11 & $7,4 \pm 0,89$ & $5,6 \pm 1,94$ & $5,8 \pm 1,92$ & $6,2 \pm 1,78$ \\
\hline 12 & $7,6 \pm 0,54$ & $5,8 \pm 2,16$ & $5,0 \pm 1,87$ & $6,6 \pm 1,94$ \\
\hline 13 & $7,8 \pm 0,44$ & $4,6 \pm 2,07$ & $5,0 \pm 1,87$ & $6,8 \pm 1,64$ \\
\hline 14 & $8,4 \pm 0,89$ & $4,6 \pm 2,07$ & $3,6 \pm 1,14$ & $6,4 \pm 1,67$ \\
\hline 15 & $8,4 \pm 0,89$ & $4,4 \pm 1,67$ & $3,4 \pm 1,14$ & $6,0 \pm 1,00$ \\
\hline 16 & $8,8 \pm 0,44$ & $4,2 \pm 1,92$ & $3,8 \pm 1,48$ & $5,4 \pm 1,51$ \\
\hline 17 & $8,8 \pm 0,44$ & $3,8 \pm 1,78$ & $3,6 \pm 1,51$ & $5,2 \pm 1,30$ \\
\hline 18 & $8,6 \pm 0,54$ & $2,8 \pm 1,78$ & $3,4 \pm 1,67$ & $4,8 \pm 1,30$ \\
\hline 19 & $8,8 \pm 0,44$ & $3,4 \pm 1,67$ & $3,4 \pm 1,67$ & $4,2 \pm 1,09$ \\
\hline 20 & $8,8 \pm 0,44$ & $3,4 \pm 1,67$ & $3,4 \pm 1,67$ & $4,0 \pm 1,00$ \\
\hline 21 & $8,8 \pm 0,44$ & $3,0 \pm 1,22$ & $3,2 \pm 1,30$ & $4,2 \pm 1,30$ \\
\hline 22 & $8,8 \pm 0,44$ & $2,8 \pm 1,30$ & $3,0 \pm 1,22$ & $4,2 \pm 1,30$ \\
\hline 23 & $8,8 \pm 0,44$ & $2,8 \pm 1,30$ & $3,0 \pm 1,22$ & $4,2 \pm 1,30$ \\
\hline 24 & $8,4 \pm 0,89$ & $3,0 \pm 1,22$ & $3,0 \pm 1,22$ & $4,0 \pm 1,00$ \\
\hline 25 & $8,6 \pm 0,89$ & $3,0 \pm 1,22$ & $3,0 \pm 1,22$ & $3,8 \pm 1,09$ \\
\hline 26 & $9,0 \pm 0,00$ & $3,0 \pm 1,22$ & $3,4 \pm 1,67$ & $3,8 \pm 1,09$ \\
\hline 27 & $9,0 \pm 0,00$ & $2,8 \pm 1,30$ & $3,4 \pm 1,67$ & $3,6 \pm 1,34$ \\
\hline 28 & $8,4 \pm 1,34$ & $2,4 \pm 0,89$ & $3,4 \pm 1,67$ & $3,6 \pm 1,34$ \\
\hline 29 & $8,4 \pm 1,34$ & $2,6 \pm 0,89$ & $3,4 \pm 1,67$ & $3,6 \pm 1,34$ \\
\hline 30 & $8,4 \pm 1,34$ & $2,4 \pm 0,54$ & $3,4 \pm 1,67$ & $3,8 \pm 1,64$ \\
\hline
\end{tabular}

rio. Não foi observada rejeição nos enxertos dos grupos T0 e T7. No grupo T9, também não se observou rejeição nos enxertos no período estudado, exceto em um animal. Mas mesmo este único animal do grupo T9 que apresentou rejeição clinicamente, o fez de forma breve, pois apresentou aumento dos parâmetros clínicos relacionados com rejeição no $11^{\circ}$ dia pós-operatório que persistiu apenas até o $14^{\circ}$ dia, ocorrendo melhora progressiva dos sinais de rejeição até o final do período em estudo.

Todos os animais que receberam ciclosporina no pósoperatório (grupos T0, T7 e T9) apresentaram enxertos classificados como não rejeitados no final do período de 30 dias, diferentemente de todos os enxertos do grupo controle que foram classificados como rejeitados. Não obstante, opacificação, edema e neovasos foram sempre mais acentuadas nos enxertos do grupo T9 comparados com os grupos T0 e T7, com mais evidência próximo ao $14^{\circ}$ dia e diminuindo próximo ao $30^{\circ}$ dia pós-transplante.

A opacificação, edema e neovascularização dos enxertos do grupo controle foram nitidamente mais acentuados do que os outros grupos tratados com ciclosporina, durante todo o período de estudo.

A figura e a tabela 2 mostram a média diária da opacidade dos enxertos corneanos nos diferentes grupos onde se observa avaliação clínica alta no grupo controle (3,5 ou mais) a partir do $9^{\circ}$ até $\mathrm{o} 30^{\circ}$ dia pós-operatório, ao contrário dos outros grupos onde a opacidade corneal tende a diminuir neste período.
A figura e a tabela 3 mostram a média diária do edema dos enxertos corneanos nos diferentes grupos, onde se observa avaliação clínica alta do edema do enxerto ( 1,8 ou mais) entre o $7^{\circ}$ e $30^{\circ}$ pós-operatório no grupo controle e o início da tendência a regressão do edema entre o $9^{\circ}$ e $12^{\circ}$ dia pósoperatório nos demais grupos, com sua diminuição progressiva até o $30^{\circ}$ dia.

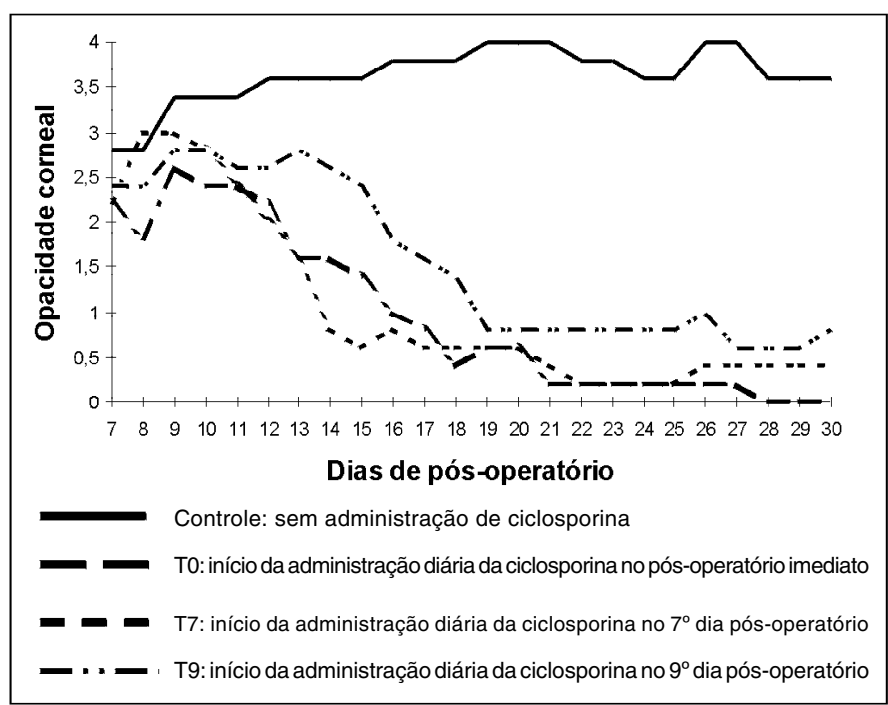

Fig. 2 - Média da opacidade dos enxertos corneanos nos diferentes grupos.

\begin{tabular}{|c|c|c|c|c|}
\hline \multirow{2}{*}{$\begin{array}{l}\text { Dias de Pós- } \\
\text { Operatório }\end{array}$} & \multicolumn{4}{|c|}{ Grupos } \\
\hline & Controle & T0 & T7 & T9 \\
\hline 7 & $2,8 \pm 0,83$ & $2,2 \pm 1,09$ & $2,2 \pm 0,44$ & $2,4 \pm 0,54$ \\
\hline 8 & $2,8 \pm 0,83$ & $1,8 \pm 1,09$ & $3,0 \pm 0,00$ & $2,4 \pm 0,54$ \\
\hline 9 & $3,4 \pm 0,89$ & $2,6 \pm 1,14$ & $3,0 \pm 0,00$ & $2,8 \pm 0,83$ \\
\hline 10 & $3,4 \pm 0,89$ & $2,4 \pm 1,14$ & $2,8 \pm 0,83$ & $3,0 \pm 0,70$ \\
\hline 11 & $3,4 \pm 0,89$ & $2,4 \pm 1,14$ & $2,4 \pm 1,14$ & $2,6 \pm 1,14$ \\
\hline 12 & $3,6 \pm 0,54$ & $2,2 \pm 0,83$ & $2,0 \pm 1,22$ & $2,6 \pm 1,14$ \\
\hline 13 & $3,6 \pm 0,54$ & $1,6 \pm 0,89$ & $1,6 \pm 1,51$ & $2,8 \pm 0,83$ \\
\hline 14 & $3,6 \pm 0,54$ & $1,6 \pm 0,89$ & $0,8 \pm 0,83$ & $2,6 \pm 0,89$ \\
\hline 15 & $3,6 \pm 0,54$ & $1,4 \pm 0,54$ & $0,6 \pm 0,89$ & $2,4 \pm 0,54$ \\
\hline 16 & $3,8 \pm 0,44$ & $1,0 \pm 0,70$ & $0,8 \pm 0,83$ & $1,8 \pm 1,09$ \\
\hline 17 & $3,8 \pm 0,44$ & $0,8 \pm 0,83$ & $0,6 \pm 0,89$ & $1,6 \pm 0,89$ \\
\hline 18 & $3,8 \pm 0,44$ & $0,4 \pm 0,89$ & $0,6 \pm 0,89$ & $1,4 \pm 0,89$ \\
\hline 19 & $4,0 \pm 0,00$ & $0,6 \pm 0,89$ & $0,6 \pm 0,89$ & $0,8 \pm 0,83$ \\
\hline 20 & $4,0 \pm 0,00$ & $0,6 \pm 0,89$ & $0,6 \pm 0,89$ & $0,8 \pm 0,83$ \\
\hline 21 & $4,0 \pm 0,00$ & $0,2 \pm 0,44$ & $0,4 \pm 0,54$ & $0,8 \pm 0,83$ \\
\hline 22 & $3,8 \pm 0,44$ & $0,2 \pm 0,44$ & $0,2 \pm 0,44$ & $0,8 \pm 0,83$ \\
\hline 23 & $3,8 \pm 0,44$ & $0,2 \pm 0,44$ & $0,2 \pm 0,44$ & $0,8 \pm 0,83$ \\
\hline 24 & $3,6 \pm 0,89$ & $0,2 \pm 0,44$ & $0,2 \pm 0,44$ & $0,8 \pm 0,83$ \\
\hline 25 & $3,6 \pm 0,89$ & $0,2 \pm 0,44$ & $0,2 \pm 0,44$ & $0,8 \pm 0,83$ \\
\hline 26 & $4,0 \pm 0,00$ & $0,2 \pm 0,44$ & $0,4 \pm 0,89$ & $1,0 \pm 0,70$ \\
\hline 27 & $4,0 \pm 0,00$ & $0,2 \pm 0,44$ & $0,4 \pm 0,89$ & $0,6 \pm 0,89$ \\
\hline 28 & $3,6 \pm 0,89$ & $0,0 \pm 0,00$ & $0,4 \pm 0,89$ & $0,6 \pm 0,89$ \\
\hline 29 & $3,6 \pm 0,89$ & $0,0 \pm 0,00$ & $0,4 \pm 0,89$ & $0,6 \pm 0,89$ \\
\hline 30 & $3,6 \pm 0,89$ & $0,0 \pm 0,00$ & $0,4 \pm 0,89$ & $0,8 \pm 0,83$ \\
\hline
\end{tabular}


A figura e a tabela 4 mostram a média diária da neovascularização dos enxertos corneanos nos diferentes grupos, onde se observa neovascularização progressiva em todos os grupos, permanecendo com avaliações clínicas altas ( 2 ou mais) entre o $14^{\circ}$ e $30^{\circ}$ dia pós-operatório. A média do grupo controle é discretamente maior que os demais grupos neste período.

A figura 5 mostra a curva de sobrevida dos enxertos corneanos nos diferentes grupos, onde se observa a falência de todos

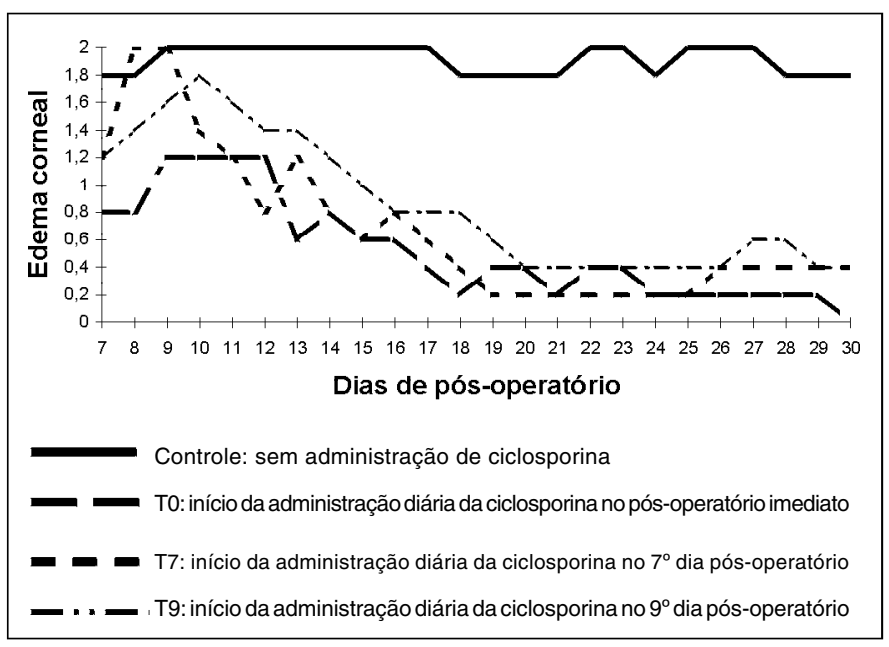

Fig. 3 - Média do edema dos enxertos corneanos nos diferentes grupos

\begin{tabular}{|c|c|c|c|c|}
\hline \multicolumn{5}{|c|}{$\begin{array}{l}\text { Tabela 3. Média e desvios-padrão do edema dos enxertos } \\
\text { corneanos nos diferentes grupos }\end{array}$} \\
\hline \multirow{2}{*}{$\begin{array}{c}\text { Dias de Pós- } \\
\text { Operatório }\end{array}$} & \multicolumn{4}{|c|}{ Grupos } \\
\hline & Controle & TO & T7 & T9 \\
\hline 7 & $1,8 \pm 0,44$ & $0,8 \pm 0,83$ & $1,2 \pm 0,44$ & $1,4 \pm 0,54$ \\
\hline 8 & $1,8 \pm 0,44$ & $0,8 \pm 0,44$ & $2,0 \pm 0,00$ & $1,4 \pm 0,54$ \\
\hline 9 & $2,0 \pm 0,00$ & $1,2 \pm 0,83$ & $2,0 \pm 0,00$ & $1,6 \pm 0,54$ \\
\hline 10 & $2,0 \pm 0,00$ & $1,2 \pm 0,83$ & $1,4 \pm 0,54$ & $1,8 \pm 0,44$ \\
\hline 11 & $2,0 \pm 0,00$ & $1,2 \pm 0,83$ & $1,2 \pm 0,83$ & $1,6 \pm 0,54$ \\
\hline 12 & $2,0 \pm 0,00$ & $1,2 \pm 0,83$ & $0,8 \pm 0,83$ & $1,4 \pm 0,54$ \\
\hline 13 & $2,0 \pm 0,00$ & $0,6 \pm 0,89$ & $1,2 \pm 0,44$ & $1,4 \pm 0,54$ \\
\hline 14 & $2,0 \pm 0,00$ & $0,6 \pm 0,89$ & $0,8 \pm 0,44$ & $1,2 \pm 0,83$ \\
\hline 15 & $2,0 \pm 0,00$ & $0,6 \pm 0,89$ & $0,6 \pm 0,54$ & $1,0 \pm 0,70$ \\
\hline 16 & $2,0 \pm 0,00$ & $0,6 \pm 0,89$ & $0,8 \pm 0,44$ & $0,8 \pm 0,44$ \\
\hline 17 & $2,0 \pm 0,00$ & $0,4 \pm 0,54$ & $0,8 \pm 0,44$ & $0,8 \pm 0,44$ \\
\hline 18 & $1,8 \pm 0,44$ & $0,2 \pm 0,44$ & $0,4 \pm 0,54$ & $0,8 \pm 0,44$ \\
\hline 19 & $1,8 \pm 0,44$ & $0,4 \pm 0,54$ & $0,2 \pm 0,44$ & $0,6 \pm 0,54$ \\
\hline 20 & $1,8 \pm 0,44$ & $0,4 \pm 0,54$ & $0,2 \pm 0,44$ & $0,4 \pm 0,54$ \\
\hline 21 & $1,8 \pm 0,44$ & $0,2 \pm 0,44$ & $0,2 \pm 0,44$ & $0,4 \pm 0,54$ \\
\hline 22 & $2,0 \pm 0,00$ & $0,4 \pm 0,54$ & $0,2 \pm 0,44$ & $0,4 \pm 0,54$ \\
\hline 23 & $2,0 \pm 0,00$ & $0,4 \pm 0,54$ & $0,2 \pm 0,44$ & $0,4 \pm 0,54$ \\
\hline 24 & $1,8 \pm 0,44$ & $0,2 \pm 0,44$ & $0,2 \pm 0,44$ & $0,4 \pm 0,54$ \\
\hline 25 & $2,0 \pm 0,00$ & $0,2 \pm 0,44$ & $0,2 \pm 0,44$ & $0,4 \pm 0,54$ \\
\hline 26 & $2,0 \pm 0,00$ & $0,2 \pm 0,44$ & $0,4 \pm 0,54$ & $0,4 \pm 0,54$ \\
\hline 27 & $2,0 \pm 0,00$ & $0,2 \pm 0,44$ & $0,4 \pm 0,54$ & $0,6 \pm 0,54$ \\
\hline 28 & $1,8 \pm 0,44$ & $0,2 \pm 0,44$ & $0,4 \pm 0,54$ & $0,6 \pm 0,54$ \\
\hline 29 & $1,8 \pm 0,44$ & $0,2 \pm 0,44$ & $0,4 \pm 0,54$ & $0,4 \pm 0,54$ \\
\hline 30 & $1,8 \pm 0,44$ & $0,0 \pm 0,00$ & $0,4 \pm 0,54$ & $0,4 \pm 0,54$ \\
\hline
\end{tabular}

os enxertos até o $19^{\circ}$ dia pós-operatório no grupo controle e a sobrevivência de todas as córneas transplantadas dos grupos T0 e T7, durante o período de estudo; no grupo T9 observa-se a falência de um enxerto no $11^{\circ}$ dia pós-operatório e as demais córneas sobrevivendo até o $30^{\circ}$ dia pós-operatório.

A figura 6A é um exemplo de enxerto corneano considerado não rejeitado, classificado clinicamente como apresentando opacidade igual a 0 , edema igual a 1 , neovascularização

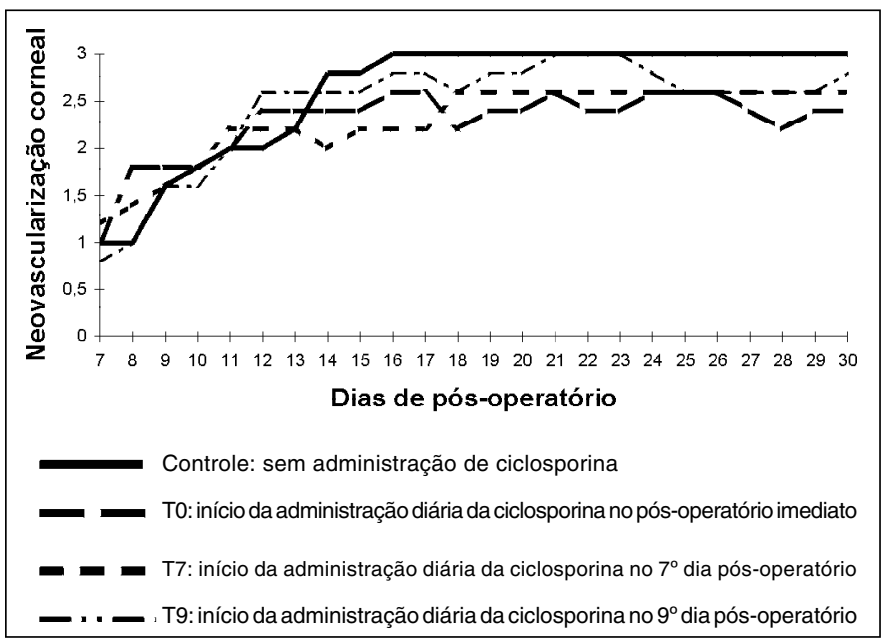

Fig. 4-Média da neovascularização dos enxertos corneanos nos diferentes grupos

\begin{tabular}{|c|c|c|c|c|}
\hline \multirow{2}{*}{$\begin{array}{c}\text { Dias de Pós- } \\
\text { Operatório }\end{array}$} & \multicolumn{4}{|c|}{ Grupos } \\
\hline & Controle & TO & T7 & T9 \\
\hline 7 & $2,0 \pm 0,00$ & $1,0 \pm 0,00$ & $1,2 \pm 0,44$ & $0,8 \pm 0,44$ \\
\hline 8 & $2,0 \pm 0,00$ & $1,8 \pm 0,44$ & $1,4 \pm 0,54$ & $1,0 \pm 0,70$ \\
\hline 9 & $3,0 \pm 0,00$ & $1,8 \pm 0,31$ & $1,6 \pm 0,54$ & $1,6 \pm 0,54$ \\
\hline 10 & $3,0 \pm 0,00$ & $1,8 \pm 0,44$ & $1,8 \pm 0,44$ & $1,6 \pm 0,54$ \\
\hline 11 & $3,0 \pm 0,00$ & $2,0 \pm 0,70$ & $2,2 \pm 0,44$ & $1,8 \pm 0,83$ \\
\hline 12 & $3,0 \pm 0,00$ & $2,4 \pm 0,54$ & $2,2 \pm 0,44$ & $2,4 \pm 0,54$ \\
\hline 13 & $3,0 \pm 0,00$ & $2,4 \pm 0,54$ & $2,2 \pm 0,44$ & $2,6 \pm 0,54$ \\
\hline 14 & $3,0 \pm 0,00$ & $2,4 \pm 0,54$ & $2,0 \pm 0,00$ & $2,6 \pm 0,54$ \\
\hline 15 & $3,0 \pm 0,00$ & $2,4 \pm 0,54$ & $2,2 \pm 0,44$ & $2,6 \pm 0,54$ \\
\hline 16 & $3,0 \pm 0,00$ & $2,6 \pm 0,54$ & $2,2 \pm 0,44$ & $2,8 \pm 0,44$ \\
\hline 17 & $3,0 \pm 0,00$ & $2,6 \pm 0,54$ & $2,2 \pm 0,44$ & $2,8 \pm 0,44$ \\
\hline 18 & $3,0 \pm 0,00$ & $2,2 \pm 0,44$ & $2,4 \pm 0,54$ & $2,6 \pm 0,89$ \\
\hline 19 & $3,0 \pm 0,00$ & $2,4 \pm 0,54$ & $2,6 \pm 0,54$ & $2,8 \pm 0,44$ \\
\hline 20 & $3,0 \pm 0,00$ & $2,4 \pm 0,54$ & $2,6 \pm 0,54$ & $2,8 \pm 0,44$ \\
\hline 21 & $3,0 \pm 0,00$ & $2,6 \pm 0,54$ & $2,6 \pm 0,54$ & $3,0 \pm 0,00$ \\
\hline 22 & $3,0 \pm 0,00$ & $2,4 \pm 0,54$ & $2,6 \pm 0,54$ & $3,0 \pm 0,00$ \\
\hline 23 & $3,0 \pm 0,00$ & $2,4 \pm 0,54$ & $2,6 \pm 0,54$ & $3,0 \pm 0,00$ \\
\hline 24 & $2,8 \pm 0,44$ & $2,6 \pm 0,54$ & $2,6 \pm 0,54$ & $2,8 \pm 0,44$ \\
\hline 25 & $2,8 \pm 0,44$ & $2,6 \pm 0,54$ & $2,6 \pm 0,54$ & $2,6 \pm 0,54$ \\
\hline 26 & $2,2 \pm 0,44$ & $2,6 \pm 0,54$ & $2,6 \pm 0,54$ & $2,6 \pm 0,54$ \\
\hline 27 & $1,0 \pm 0,00$ & $2,4 \pm 0,54$ & $2,6 \pm 0,54$ & $2,6 \pm 0,54$ \\
\hline 28 & $1,0 \pm 0,00$ & $2,2 \pm 0,44$ & $2,6 \pm 0,54$ & $2,6 \pm 0,54$ \\
\hline 29 & $1,6 \pm 0,54$ & $2,4 \pm 0,54$ & $2,6 \pm 0,54$ & $2,6 \pm 0,54$ \\
\hline 30 & $1,8 \pm 0,44$ & $2,4 \pm 0,54$ & $2,6 \pm 0,54$ & $2,8 \pm 0,44$ \\
\hline
\end{tabular}




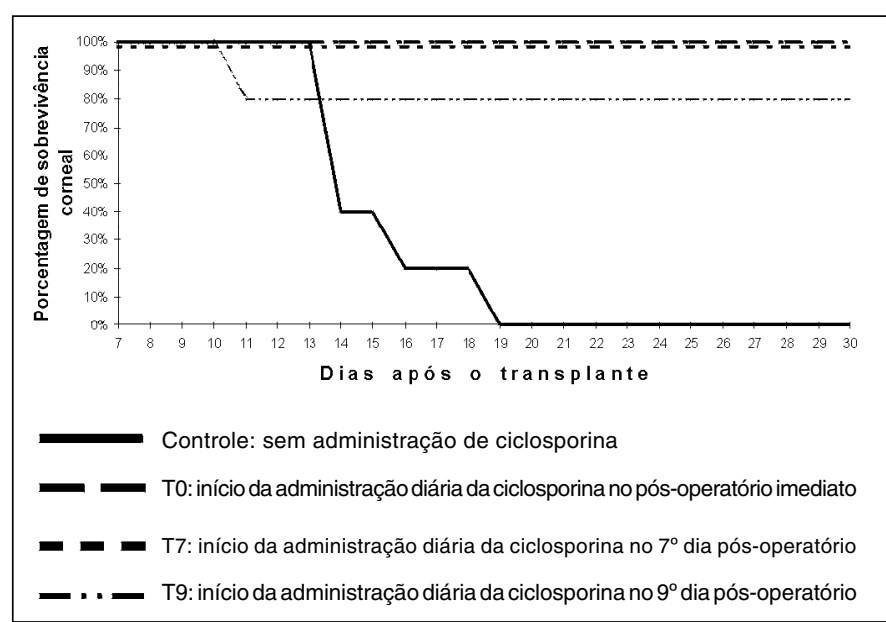

Fig. 5 - Curva de sobrevida dos enxertos corneanos

igual a 2. Trata-se de animal pertencente ao grupo $\mathrm{T} 7$ no $17^{\circ}$ pós-operatório. A Figura $6 \mathrm{~B}$ é um exemplo de enxerto corneano considerado rejeitado, classificado clinicamente como apresentando opacidade igual a 4, edema igual a 2, neovascularização igual a 3 . Trata-se de animal pertencente ao grupo controle no $27^{\circ}$ dia pós-operatório.

Diarréia foi observada em todos os animais que receberam ciclosporina.

\section{Avaliação histológica}

A tabela 5 mostra a avaliação histológica dos enxertos no $30^{\circ}$ dia pós-transplante de córnea. Os estudos histológicos mostraram infiltrado inflamatório mais intenso nas córneas do grupo controle, onde não se utilizou ciclosporina. O predomínio de linfócitos sobre os neutrófilos é bastante evidente no grupo controle, confirmando os achados clínicos relacionados com rejeição imunológica. Fibrose e neovasos são também mais evidentes neste grupo se comparado aos demais grupos que receberam ciclosporina. A figura 7A mostra corte histológico de enxerto corneano do grupo tratado com ciclosporina no $30^{\circ}$ dia pós-operatório com raras células inflamatórias, considerado não rejeitado. A figura 7B mostra corte histológico de enxerto corneano do grupo não tratado com ciclosporina no $30^{\circ}$ dia pós-operatório com infiltrado de células mononucleares intenso, considerado rejeitado.

\section{DISCUSSÃO}

Rejeição é a maior causa de falências tardias do transplante de córnea ${ }^{14}$. A situação é mais dramática nos casos de córneas vascularizadas e quando já houve rejeição prévia do enxerto, pois os índices de falência do transplante de córnea superam os $50 \%$, apesar do uso intensivo de corticosteróides ${ }^{15}$.

Vários trabalhos publicados na literatura mostram diminuição nos índices de rejeição nos transplantes penetrantes de córnea quando se utiliza ciclosporina isolada ou em associação a outras drogas, como os corticosteróides ${ }^{2,5,16}$. A ciclosporina atua prevenindo a maturação dos linfócitos $\mathrm{T}^{17}$ que sabe-se estar relacionado com o processo imune da rejeição de córnea ${ }^{18}$. Ela tem a vantagem de ter ação na imunidade celular altamente específica, em contraste aos corticosteróides que tem efeito imunossupressor generalizado sobre o sistema imunocompetente. Esta característica associada a aparente mínima mielotoxicidade, faz desta droga um agente especialmente atraente como droga imunossupressora em vários modelos de transplantes ${ }^{2}$. Estudos mostram menor toxicidade da ciclosporina se comparada a outras drogas como FK506 e a 15-deoxyspergualin ${ }^{19}$.

Para testar o efeito da ciclosporina neste estudo foi utilizado um modelo experimental em rato. Utilizou-se animais isogênicos para se obter reações imunológicas reproduzíveis em relação ao enxerto, devido a discrepância constante de histocompatibilidade ${ }^{11}$. A diferença de gênero dos animais utilizados não parece influir na rejeição imunológica, haja visto que ela não ocorreu em experimentos preliminares, quando se utilizou doadores e receptores de raças isogênicas.

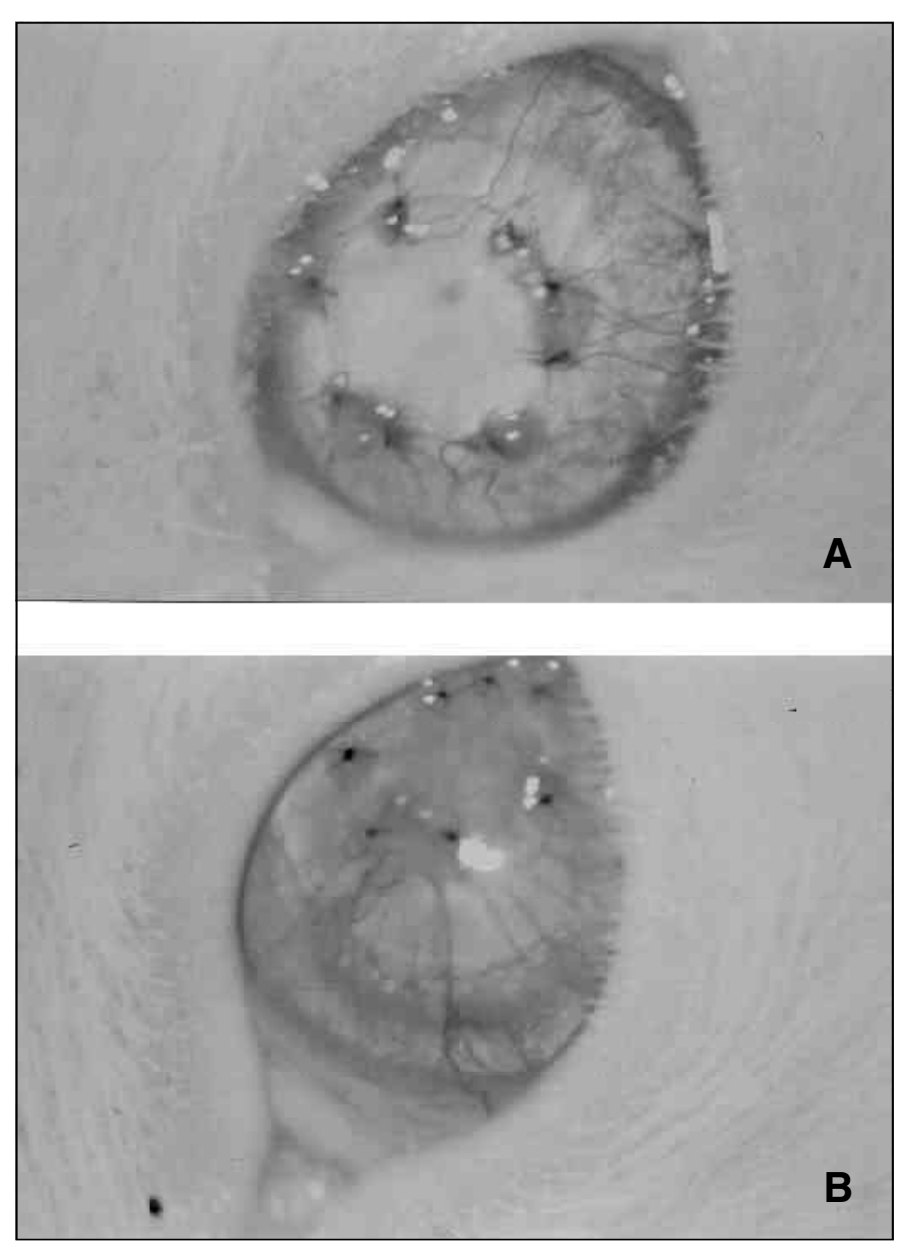

Fig. 6 - (A) Enxerto corneano de rato do grupo T7 considerado não rejeitado, no $17^{\circ}$ dia pós-transplante de córnea (Avaliação clínica: opacidade $=0$, edema $=1$ e neovascularização $=2$ ). (B) Enxerto corneano de rato do grupo controle considerado rejeitado, no $27^{\circ}$ dia pós-transplante de córnea (Avaliação clínica: opacidade $=4$, edema $=$ 2 e neovascularização $=3$ ) 


\begin{tabular}{|c|c|c|c|}
\hline \multicolumn{4}{|c|}{$\begin{array}{l}\text { Tabela 5. Avaliação histológica dos enxertos no } 30^{\circ} \text { dia pós- } \\
\text { transplante de córnea }\end{array}$} \\
\hline $\begin{array}{l}\text { Grau de } \\
\text { Inflamação }\end{array}$ & $\begin{array}{c}\text { Células } \\
\text { (Predomínio) }\end{array}$ & Neovasos & Fibrose \\
\hline \multicolumn{4}{|c|}{ Controles } \\
\hline+ & L & + & ++ \\
\hline+++ & $L>N$ & ++ & ++ \\
\hline+++ & $L \gg N$ & ++ & +++ \\
\hline+++ & $L \gg N$ & ++ & +++ \\
\hline++ & $L>N$ & ++ & +++ \\
\hline \multicolumn{4}{|c|}{ TO } \\
\hline+ & L & + & +++ \\
\hline+ & $N>L$ & ++ & + \\
\hline+ & $\mathrm{L}=\mathrm{N}$ & ++ & ++ \\
\hline+ & $L>N$ & + & + \\
\hline+ & $L>N$ & + & + \\
\hline \multicolumn{4}{|c|}{ T7 } \\
\hline 0 & $\mathrm{~L}$ raros & 0 & 0 \\
\hline+ & $L>N$ & + & + \\
\hline+ & $L>N$ & + & + \\
\hline+ & $L>N$ & ++ & + \\
\hline+ & $N>L$ & + & + \\
\hline \multicolumn{4}{|c|}{ T9 } \\
\hline+ & $L>N$ & 0 & 0 \\
\hline+ & L & + & + \\
\hline+ & $\mathrm{L}$ & + & + \\
\hline+ & $N>L$ & ++ & ++ \\
\hline++ & $N>L$ & + & ++ \\
\hline $\begin{array}{l}0=\text { ausência } \\
+=\text { leve }\end{array}$ & $\begin{array}{l}++=\bmod \\
+++=\text { ace }\end{array}$ & (a) & $\begin{array}{l}L=\text { Linfócitos } \\
N=\text { Neutrófilos }\end{array}$ \\
\hline
\end{tabular}

A ciclosporina é um metabólito fúngico originalmente isolado de culturas da Cylindrocarpon lucidum. O mecanismo de ação das suas propriedades imunossupressoras não é totalmente conhecido. A ciclosporina tem demonstrado suprimir várias funções dos linfócitos $\mathrm{T}$ in vivo e in vitro, além da ativação de células de apresentação do antígeno, assim como a liberação de linfocinas ${ }^{20}$; seu efeito supressor é mínimo sobre funções dos linfócitos B. Atualmente, já é evidente que a ciclosporina atua inibindo a expressão de receptores de membrana para IL-2 além de inibir a produção de IL-2 pelos linfócitos $\mathrm{T}$ auxiliadores ${ }^{2}$. Estudos mais recentes mostram que o mecanismo de ação da ciclosporina parece ser o bloqueio da ativação das células $\mathrm{T}$ no estágio precoce do ciclo celular em $\mathrm{G}_{0}$ (intervalo do ciclo celular no qual a proliferação celular está interrompida) e $\mathrm{G}_{1}$ (intervalo do ciclo celular que antecede a síntese de DNA- ácido desoxiribonucleico), limitando a transcrição do ácido ribonucleico mensageiro em codificar IL-2. A ciclosporina liga-se a ciclofilina a qual inibe a indução do fator nuclear de ativação de células $T$, via calcineurina. Conseqüentemente, a transcrição do gene da IL2 é interrompida ${ }^{21}$.

Apesar de se conhecer o efeito benéfico da ciclosporina, pela sua ação nas fases iniciais da sensibilização antigênica sobre a sobrevivência do enxerto, alguns pontos ainda são controversos. Não está estabelecido até agora se a ciclosporina tem efeito sobre fases mais tardias do processo de rejeição.

Foets et al. ${ }^{7}$ obtiveram êxito em reverter episódios iniciais da rejeição aumentando a dose tópica da ciclosporina, enquando Roussel et al. ${ }^{22}$ observaram que os episódios iniciais somente poderiam ser atenuados mas não revertidos.

No nosso modelo experimental, os parâmetros clínicos do grupo controle começaram a se diferenciar dos demais grupos em torno do $8^{\circ}$ e $9^{\circ}$ dia pós-operatório, sugerindo início do processo de rejeição. As avaliações clínicas e estatísticas foram realizadas a partir do $7^{\circ}$ dia pós-operatório, pois todos os grupos apresentaram médias de avaliações clínicas semelhantes antes deste período durante os experimentos pilotos, possivelmente pela presença de inflamação não específica pós-cirúrgica, não relacionada com o processo de rejeição imunológica. O índice superior a 8, utilizado para definir rejeição, foi adotado observando-se as médias dos parâmetros clínicos dos grupos controle e T0 no início da diferenciação imunológica. No grupo tratado com ciclosporina, a diferença com o grupo controle sem tratamento é notada em torno do $13^{\circ}$

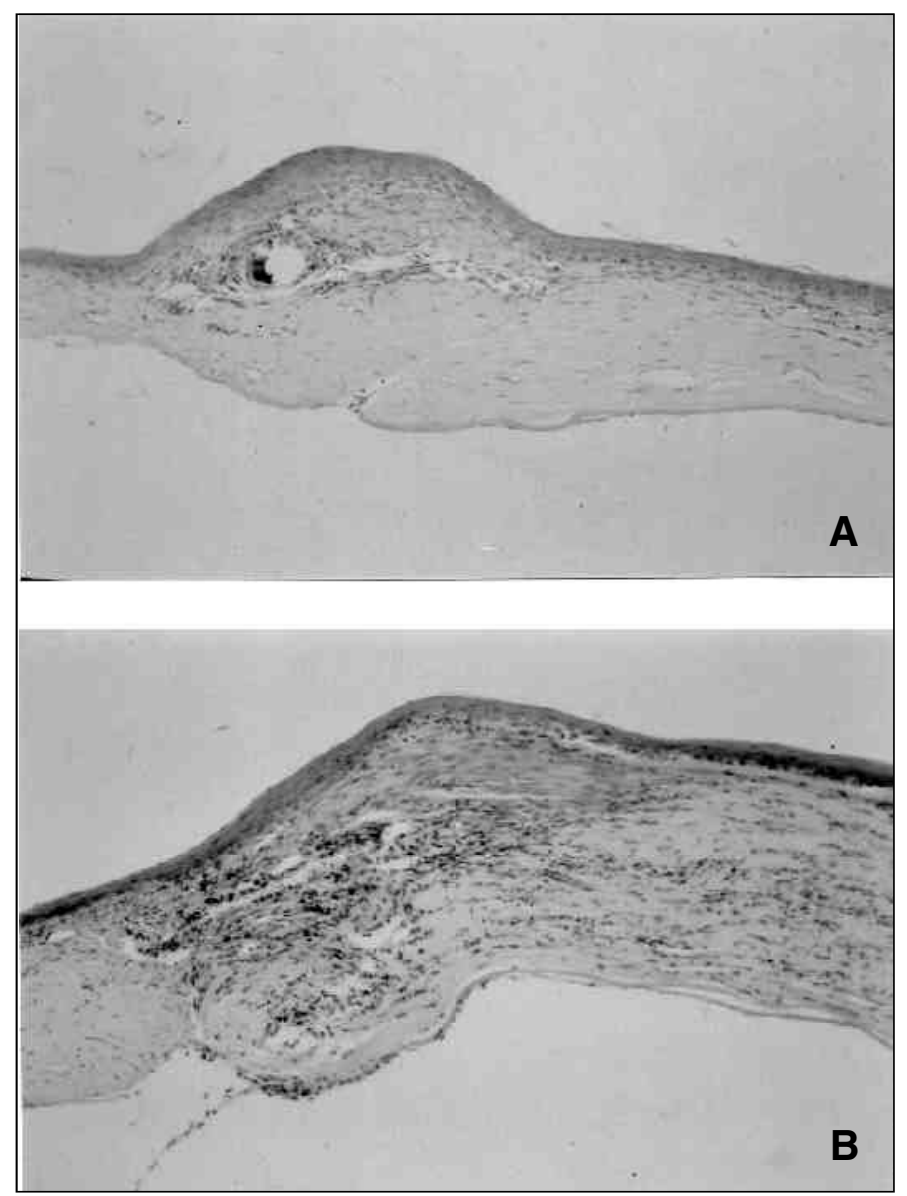

Fig. 7 - (A) Corte histológico de enxerto corneano do grupo tratado com ciclosporina no $30^{\circ}$ dia de pós-operatório com raras células inflamatórias, corado pela técnica da hematoxilina-eosina (40x). (B) Corte histológico de enxerto corneano do grupo não tratado com ciclosporina no $30^{\circ}$ dia de pós-operatório com infiltrado de células mononucleares intenso, corado pela técnica da hematoxilina-eosina (150x) 
e $14^{\circ}$ dia pós-operatório. Nestes dias, a soma de dois desviospadrão mais a média do grupo T0 foi igual a 8,74 e este valor foi considerado como certamente relacionado a rejeição em se tratando de um grupo que teoricamente estaria protegido deste fenômeno por usar o imunossupressor ciclosporina desde o pós-operatório imediato do transplante de córnea. Desta forma a soma dos parâmetros clínicos maiores que 8 foram considerados rejeição.

A ciclosporina foi utilizada no nosso estudo em 3 grupos distintos: a) a partir do dia do transplante, b) antes da manifestação dos sinais de rejeição com provável reconhecimento imunológico a partir do $7^{\circ}$ dia pós-operatório, c) período imediatamente anterior ao início da rejeição clínica observada no grupo controle a partir do $9^{\circ}$ dia pós-operatório, onde certamente a sensibilização ao aloantígeno já foi processada e a fase efetora da rejeição imunológica dá sinais de início de instalação. Todos os animais do grupo controle tiveram seus enxertos rejeitados, sendo que 3 deles evoluíram para rejeição no $14^{\circ}$ dia e os outros 2 até o $19^{\circ}$ dia pós-transplante. Comparando-se os índices de opacidade, edema e neovascularização do grupo controle com os demais grupos tratados com ciclosporina, observou-se índices superiores no grupo controle. Os índices das variáveis clínicas (opacidade, edema e neovascularização) neste grupo, se mantiveram elevados até o final dos 30 dias de experimento. Os achados histológicos mostraram infiltrado inflamatório, neovasos e fibrose mais intensos nesta fase do pós-operatório no grupo controle, o que confirmou os achados clínicos.

A opacificação e o edema da córnea provavelmente são sinais clínicos relacionados com a perda da função endotelial por rejeição imunológica, além de infiltração celular que é demonstrada no exame histológico, e a neovascularização talvez esteja ligada aos estímulos inflamatórios não específicos ocorrendo também em enxertos que receberam a ciclosporina no pós-operatório imediato que apresentam córnea transparente e sem edema.

Nos grupos T0 e T7, não se observou rejeição nos enxertos transplantados em nenhum período do estudo, demonstrando o efeito imunossupressor da ciclosporina. A histologia também confirmou os achados clínicos com índices de infiltrado inflamatório inferiores aos encontrados no grupo controle.

A exceção ficou no grupo T9, onde houve um animal com o enxerto classificado como rejeitado no $11^{\circ}$ dia pós-transplante, mas com regressão do processo a partir do $15^{\circ}$ dia pós-operatório. Isto demonstra que mesmo após a sensibilização já ter ocorrido, a ciclosporina conseguiu inibir a rejeição numa fase tardia, o que ainda não foi abordado na literatura. Os demais animais do grupo T9 não tiveram suas córneas consideradas como rejeitadas, mas mostraram índices de avaliação clínica superiores aos grupos T0 e T7. O grau de inflamação, observada no estudo histológico no grupo T9 é ligeiramente superior se comparado aos grupos T0 e T7. Isto sugere que a ação imunossupressora da ciclosporina possa ter efeito em fases tardias após a sensibilização antigênica já ter ocorrido, fazendo com que ocorra uma forma de rejeição mais branda.
As células $\mathrm{T}$ já ativadas parecem ser também alvo da atuação da ciclosporina, inibindo a apresentação de receptores de IL-2 ou a produção de IL-2, posteriormente, evitando a potencialização e o prolongamento do processo de rejeição. Assim a rejeição se manteria limitada em intensidade e duração, como observado experimentalmente.

Estes resultados sugerem que a ciclosporina possa ter algum efeito benéfico sobre o controle da rejeição mesmo na sua fase ativa. Esta informação é de grande importância clínica, pois a ciclosporina poderia ser utilizada em casos onde rejeição já estivesse instalada, abrandando ou inibindo o processo.

\section{SUMMARY}

Purpose: Corneal graft rejection suppression after intramuscular cyclosporine administration at different periods of time was studied on a penetrating keratoplasty rejection model in the rat.

Methods: Inbred Lewis rats were used as recipients and Fischer rats were used as donors in a orthotopic rejection model of corneal transplantation. Intramuscular injection of cyclosporine $10 \mathrm{mg} / \mathrm{kg}$ per day was administered up to the $30^{\text {th }}$ postoperative day in 3 groups with different starting periods: at the day of surgery, at the $7^{\text {th }}$, and at the $9^{\text {th }}$ postoperative day. Grafts were evaluated through clinical and histological examination.

Results: The corneal grafts developed a $100 \%$ rejection in about 3 weeks after the penetrating keratoplasty in the control group $(n=5)$ in which no cyclosporine was administered. Graft rejection was detected in one case in the groups in which cyclosporine was administered $(n=15)$, but the process was inhibited during the study period. Histological studies confirmed the clinical evaluations.

Conclusions: These data indicate that intramuscular cyclosporine may control the corneal graft rejection, even during the active phase.

Keywords: Cyclosporine A; Keratoplasty; experimental penetrating; Graft rejection.

\section{REFERÊNCIAS BIBLIOGRÁFICAS}

1. Coster DJ. Mechanisms of corneal graft failure: the erosion of corneal privilege. Eye 1989;3:251-62.

2. Salisbury JD, Gebhardt BM. Suppression of corneal allograft rejection by cyclosporin A. Arch Ophthalmol 1981;99:1640-3.

3. Polack FM. Keratoplasty and intraocular lenses. Cornea 1985-86;4:137-47.

4. Stern GA. Update on the medical management of corneal and external eye diseases, corneal transplantation and keratorefractive surgery. Ophthalmology 1988;95:842-54.

5. Shepherd WF, Coster DJ, Fook TC, Rice NS, Jones BR. Effect of cyclosporin A on the survival of corneal allografts in rabbits. Br J Ophtalmol 1980;64:148-53.

6. Miller K, Huber C, Niederwieser D, Göttinger W. Successful engraftment of high-risk corneal allografts with short-term immunosuppression with cyclosporine. Transplantation 1988;45:651-3.

7. Foets B, Missotten L, Vanderveeren O, Goossens W. Prolonged survival of allogeneic grafts in rabbits treated with topically applied ciclosporine A. 
systemic absorption and local immunosuppressive effect. $\mathrm{Br} \mathrm{J}$ Ophthalmol 1985;69:600-3.

8. Bouchard CS, Joseph C, Duffner K, Duffner L. The role of systemic cyclosponine dosing schedule on corneal allograft survival in the rat model. Short Communication. Curr Eye Res 1995;14:421-4.

9. Borel JF, Kis ZL. The Discovery and Development of Cyclosporine (Sandimmune). Transplantation Proceedings, 1991;23:1867-74.

10. Gill TJ 3d, Kunz HW, Misra DN, Hassett AL. The major histocompatibility of the rat. Transplantation 1987;43:773-85.

11. Herbort CP, Matsubara M, Nishi M, Mochizuki M. Penetrating keratoplasty in the rat: A model for the study immunosuppressive treatment of graft rejection. Jpn J Ophthalmol 1989;33:212-20.

12. Michalany J. Técnica Histológica em Anatomia Patológica, São Paulo Ed. Pedagógica e Universitária, 1980.

13. Gil S, Zarate GP. Métodos Estadísticos: Un enfoque interdiciplinário. Editoriall Trillas 1991.

14. Council on Scientific Affairs. Report of the Organ Transplant Panel. Corneal Transplantation. JAMA 1988;259:719-22.

15. Alldredge OC, Krachmer JH. Clinical types of corneal transplant rejection.
Their manifestations, frequency, preoperative correlates and treatment. Arch Ophthalmol 1981;99:599-604.

16. Hill JC. The Use of Cyclosporine in High-Risk Keratoplsty. Am J Ophthalmol 1989; 107:506-10.

17. Calne RY, White DJ, Pentlow BD, Rolles K, Syrakos T, Ohtawa T, Smith DP, McMaster P, Evans DB, Herbertson BM, Thiru S. Cyclosporin A: Preliminary observations in dogs with pancreatic duodenal allografts and patients with cadaveric renal transplants. Transplant Proc 1979;11:860-4.

18. Polack FM, Kanai A. Electron Microscopic studies of graft endothelium in corneal graft rejection. Am J Ophthalmol 1972;73:711-7.

19. Mochizuki M, Kawashima H. Effects of FK506, 15-deoxyspergualin, and cyclosporine on experimental autoimmune uveoretinitis in the rat. Autoimmunity 1990;8:37-41.

20. Kahan BD. Cyclosporine: The agent and its actions. Transplant Proc 1985; 17:5-18.

21. Belin MW, Bouchard CS, Phillips TM. Update on topical cyclosporin A: background, immunology and pharmacology. Cornea 1990;9(3)184-95.

22. Roussel TJ, Osato MS, Wilhelmus KR. Cyclosporine and experimental corneal transplantation. Transplant Proc 1983;15:3081-3.

\section{ANÚNCIO}

